\title{
Burkitt lymphoma beyond MYC translocation: N-MYC and DNA methyltransferases dysregulation
}

\author{
Giulia De Falco ${ }^{1,2}$, Maria Raffaella Ambrosio ${ }^{1}$, Fabio Fuligni ${ }^{3}$, Anna Onnis ${ }^{1}$, Cristiana Bellan ${ }^{1}$, Bruno Jim Rocca', \\ Mohsen Navari ${ }^{3}$, Maryam Etebari ${ }^{3}$, Lucia Mundo ${ }^{1}$, Sara Gazaneo ${ }^{1}$, Fabio Facchetti ${ }^{4}$, Stefano A. Pileri ${ }^{3}$, \\ Lorenzo Leoncini ${ }^{i^{*}+}$ and Pier Paolo Piccaluga ${ }^{3+}$
}

\begin{abstract}
Background: The oncogenic transcription factor MYC is pathologically activated in many human malignancies. A paradigm for MYC dysregulation is offered by Burkitt lymphoma, where chromosomal translocations leading to Immunoglobulin gene-MYC fusion are the crucial initiating oncogenic events. However, Burkitt lymphoma cases with no detectable MYC rearrangement but maintaining MYC expression have been identified and alternative mechanisms can be involved in MYC dysregulation in these cases.

Methods: We studied the microRNA profile of MYC translocation-positive and MYC translocation-negative Burkitt lymphoma cases in order to uncover possible differences at the molecular level. Data was validated at the mRNA and protein level by quantitative Real-Time polymerase chain reaction and immunohistochemistry, respectively.

Results: We identified four microRNAs differentially expressed between the two groups. The impact of these microRNAs on the expression of selected genes was then investigated. Interestingly, in MYC translocation-negative cases we found over-expression of DNA-methyl transferase family members, consistent to hypo-expression of the hsa-miR-29 family. This finding suggests an alternative way for the activation of lymphomagenesis in these cases, based on global changes in methylation landscape, aberrant DNA hypermethylation, lack of epigenetic control on transcription of targeted genes, and increase of genomic instability. In addition, we observed an over-expression of another MYC family gene member, MYCN that may therefore represent a cooperating mechanism of MYC in driving the malignant transformation in those cases lacking an identifiable MYC translocation but expressing the gene at the mRNA and protein levels.
\end{abstract}

Conclusions: Collectively, our results showed that MYC translocation-positive and MYC translocation-negative Burkitt lymphoma cases are slightly different in terms of microRNA and gene expression. MYC translocationnegative Burkitt lymphoma, similarly to other aggressive B-cell non Hodgkin's lymphomas, may represent a model to understand the intricate molecular pathway responsible for MYC dysregulation in cancer.

\section{Background}

Burkitt lymphoma (BL) is a highly aggressive B-cell nonHodgkin lymphoma characterized by peculiar clinical, morphological, immunophenotypical, cytogenetic, and gene expression profile features [1]. The current World Health Organization (WHO) classification of tumors of hematopoietic and lymphoid tissue assesses that no single parameter can be used as the gold standard to achieve the

\footnotetext{
*Correspondence: leoncinil@unisi.it

†Equal contributors

'Department of Medical Biotechnologies, University of Siena, Italy - Via delle Scotte, 6 - 53100 Siena, Italy

Full list of author information is available at the end of the article
}

diagnosis but that a combination of clinical, histological, immunophenotypical and genetic criteria is necessary [1]. The presence of the $M Y C$-associated translocation $[\mathrm{t}(8 ; 14)$ $M Y C /$ Immunoglobulin heavy chain gene $(I G H)]$ or variants is necessary to confirm all but the most classic cases. However, in the cases of otherwise typical BL, in which an evident MYC translocation cannot be detected by the standard procedures, the diagnosis of BL can still be made [1]. Five to ten percent of BL cases show no translocation, both by classical cytogenetics and molecular methods like fluorescence in situ hybridization (FISH) analysis [2, 3]. This may be due to technical failure of FISH, as these cases may present with a very small excision of $M Y C$ and

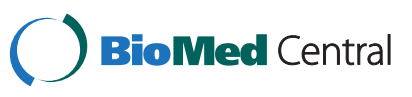

(c) 2015 De Falco et al. Open Access This article is distributed under the terms of the Creative Commons Attribution 4.0 International License (http://creativecommons.org/licenses/by/4.0/), which permits unrestricted use, distribution, and reproduction in any medium, provided you give appropriate credit to the original author(s) and the source, provide a link to the Creative Commons license, and indicate if changes were made. The Creative Commons Public Domain Dedication waiver (http://creativecommons.org/publicdomain/zero/1.0/) applies to the data made available in this article, unless otherwise stated. 
insertion of the gene into one of the IG loci, which is missed by the available probes [4]. Another option is that the breakpoint is localized far outside the region covered by the currently available FISH probes [4]. Even though none of the techniques currently used to diagnose genetic changes can unambiguously rule out all of MYC translocations [4], some observations suggest that mechanisms other than translocation are responsible for elevated MYC protein expression in BL even in the absence of genomic rearrangements $[5,6]$. Amplification, rearrangement or hypomethylation of the $M Y C$ oncogene are genetic alterations frequently occurring in many cancers, as carcinoma of the cervix, colon, breast, lung and stomach [7-11], and causing $M Y C$ to be activated and over-expressed. Previous studies, by integrating structural and functional genomics to catalogue the broad of somatic mutations in BL [12-14] have found that the most mutated gene in $\mathrm{BL}$ is $M Y C$ itself (70 \% of cases approximately). Moreover, there is increasing evidence that MYC protein over-expression may occur in tumors without apparent gene alterations [15] and it has been suggested that a dysregulated expression of microRNAs (miRNAs) may represent one of the mechanisms leading to $M Y C$ overexpression in BL cases lacking a classical $M Y C$ translocation, through either a direct or indirect mechanism [5, 6]. In recent years, lymphoma studies have uncovered various mechanisms by which miRNAs influence their target genes [16] and it has become clear that alterations in the expression of miRNAs contribute to the pathogenesis of most, if not all, human malignancies [17].

All the mechanisms leading to MYC over-expression, affect the expression of its downstream target genes that are involved in various cellular processes such as cell proliferation, cell growth, apoptosis, differentiation, and stem-cell self-renewal, presumably through DNA overreplication [18]. In addition, $M Y C$ amplifies the existing gene expression program and can also control global chromatin structure by regulating histone acetylation [19].

Increasing information identifies other essential pathways that are activated in the pathogenesis of BL and highlights the fact that $M Y C$ translocation alone is insufficient to drive lymphomagenesis. Therefore BL cases lacking the typical $M Y C$ translocation, but expressing MYC at the protein level, may represent a good model for a more detailed description of $M Y C$ regulation. In this paper we investigated the microRNA profile of $M Y C$ translocation-positive and $M Y C$ translocation-negative $\mathrm{BL}$ cases in order to uncover possible differences at the molecular level. We found that MYC translocation-positive and -negative BL cases are slightly different in terms of microRNA and gene expression, and we validated our findings at the mRNA and protein levels. Interestingly, in $M Y C$ translocation-negative BLs we found overexpression of DNA methyltransferase (DNMT) family members, consistent to hypo-expression of hsa-miR-29 family. This finding suggests an alternative way for the activation of lymphomagenesis in these cases, based on global changes in methylation landscape, aberrant DNA hypermethylation, lack of epigenetic control on transcription of targeted genes, and increase of genomic instability. In addition, we observed the over-expression of another $M Y C$ family gene member, $M Y C N$ that may therefore represent an additional mechanism for malignant transformation.

Our findings may be helpful to explain the pathogenetic mechanisms of tumors in which overexpression of $M Y C$ is independent of a chromosomal translocation or a gene amplification.

\section{Methods \\ Ethics}

This study was approved by the ethics committee of the University of Siena, Italy and of Lacor Hospital, Uganda. Study participants or their legal guardians provided written informed consent.

\section{Case selection}

109 Burkitt lymphoma cases, enrolled in the International Network for Cancer Treatment and Research (INCTR) study on African BL, were used for this study. All cases were recorded in childhood and diagnosed as BL by an expert panel on histological slides stained with Haematoxylin and Eosin (H\&E) and Giemsa, and by immunophenotyping, according to the WHO classification $[1,20]$. Ten cases did not show the typical $\mathrm{t}(8 ; 14), \mathrm{t}(8 ; 2)$ and $\mathrm{t}(8 ; 22)$ MYCtranslocations at FISH analysis (MYC translocation negative in the following) by using both dual-fusion probes and split-signal probes for $I G H$ and Immunoglobulin light chain gene (IGL) loci as well as an LSI IGH/MYC CEP 8 Tricolor dual-fusion probe (Vysis, Abbott Molecular IL, USA). FISH analysis using BCL2 and BCL6 probes was also negative. All cases were otherwise completely typical in term of clinical presentation (age: median 7, range 4-10; female/ male ratio: 4/6; nodal/extra-nodal ratio: $2 / 8$ ), morphology and immunophenotype (CD10+, BCL6+, BCL2-, CD38+, CD44-, Ki-67 $100 \%$ ) to make a diagnosis of BL.

The analysis of the EBV status was performed by in situ hybridization for EBV-encoded RNA (EBER) as previously reported [6]. In particular, 8/10 MYC translocation negative cases were EBV-positive, whereas the positivity to the virus was detected in $90 \%$ of $M Y C$ translocation positive cases.

Unfortunately, RNA extracted from formalin-fixed and paraffin-embedded (FFPE) material precluded next generation sequencing (NGS) studies in most cases, which was therefore performed only in one case, whose fresh tissue was available.

\section{RNA extraction}

For gene expression analysis, RecoverAll ${ }^{\text {six }}$ Total Nucleic Acid Isolation Kit (Life Technologies, Carlsbad, California, 
USA) was used to extract total RNA from FFPE tissues. Up to five $10 \mu \mathrm{m}$ sections were processed per reaction. FFPE samples were deparaffinised using a series of xylene and ethanol washes. Next, they were subjected to a rigorous protease digestion with an incubation time tailored for recovery of total RNA. RNA was purified using a rapid glassfiber filter methodology that includes an on-filter DNAse treatment and were eluted into the low salt buffer provided. On the other hand, for miRNA analysis RNA was extracted from FFPE sections of primary tumors and reactive lymph nodes using the miRNeasy FFPE Kit (Qiagen, Milan, Italy), according to the manufacturer's instructions.

The amount and quality of RNA were evaluated by measuring the OD at $260 \mathrm{~nm}$ and the 260/230 and 260/280 ratios using a Nanodrop spectrophotometer (Celbio, Milan, Italy). The quality of RNA was also checked using a Bioanalyzer 2100 (Agilent, CA, USA).

\section{Next generation sequencing}

High-throughput RNA sequencing produced about 66 million of 75 bp paired ends reads (theoretical coverage calculated on Ref Seq transcriptome 84X). Chromosomal translocations were detected using a bioinformatic pipeline that combines results from three different fusion-detection tools (deFuse, Chimerascan and Tophat Fusion) [21-23] and filtered on non-tumor controls using previously sequenced control reactive lymph nodes. MYC gene expression was estimated in one $M Y C$ translocation-negative sample and in other 21 endemic Burkitt lymphomas using the transcripts parts per million (TPM) calculation method [24].

Single Nucleotide Variants (SNVs) and short insertions and deletions (Indels) were called using the Genome Analysis Toolkit (GATK) [25] after mapping quality score recalibration and local realignment around indels.

Table 1 Primers used for RTqPCR. Primer sequences for DNMT1 amplified a region of $88 \mathrm{bp}$. Primers for DNMT3a amplified a region of $68 \mathrm{bp}$; Primers for DNMT3b amplified a region of $68 \mathrm{bp}$; Primers for MYC amplified a region of $129 \mathrm{bp}$; Primers for HPRT amplified a region of $191 \mathrm{bp}$

\begin{tabular}{ll}
\hline Gene & Primer sequence \\
\hline DNMT1-FORWARD & 5'-CGACTACATCAAAGGCAGCAACCTG-3' \\
DNMT1-REVERSE & 5'-TGGAGTGGACTTGTGGGTGTTCTC-3' \\
DNMT3A-FORWARD & 5'-TAT TGATGAGCGCACAAGAGAGC-3' \\
DNMT3A-REVERSE & 5'-GGGTGTTCCAGGGTAACATTGAG-3' \\
DNMT3b-FORWARD & 5'-GGCAAGTTCTCCGAGGTCTCTG-3' \\
DNMT3b-REVERSE & 5'-TGGTACATGGCTTTCGATAGGA-3' \\
MYC-FORWARD & 5'-AGCGACTCTGAGGAGGAAC-3' \\
MYC-REVERSE & 5'-TGTGAGGAGGTTGGTGTG-3' \\
HPRT-FORWARD & 5'-AGCCAGACTTTGTTGGATTTG-3' \\
HPRT-REVERSE & 5'-TTTACTGGCGATGTCAATAAG-3' \\
\hline
\end{tabular}

All of the mutations detected were filtered using tresholds based on quality, coverage and strand of the mapped reads and according to variants already present in public databases (Hapmap, dbSNP and 1000genome project) [26]. The Annovar tool [27] was used for functional annotation of variants, including exonic functions and aminoacid changes. All the mutations found in the $M Y C$ gene, including variations in intergenic, intronic and UTR regions, were manually checked and explorated using the Integrative Genomic Viewer 2.03 (IGV) visualization tool [28].

\section{MicroRNA array profiling}

MiRNA profiling was performed by an external facility (Exiqon, Copenhagen, Denmark). The samples were labelled using the miRCURY ${ }^{m}$ Hy3/Hy5 Power labelling kit and hybridized on the miRCURY ${ }^{\text {ma }}$ LNA Array $\left(5^{\text {th }}\right.$ Generation arrays, $h s a, m m u$ and $r n o$, Exiqon).

Raw data was then received and analyzed in our laboratories. Briefly, signals quantified by microarrays were processed with a normalization pipeline using MIDAS v2.22 software [29]: bad channels (intensity values less than 1) were filtered prior to normalization, and all the spots with a signal/noise value less than 2 were marked as "bad" and excluded from analysis (background correction). Signals were normalized using the global Lowess (Locally weighted scatterplot smoothing) regression algorithm [30] with a smooth parameter of 0,33 , which has been found to produce the best within-slide normalization to minimize the intensitydependent differences between the dyes. Statistical Analysis was performed using $\mathrm{MeV}$ v4.7.4 on a dataset including only human miRNA annotated on miRBase [31]. Unsupervised hierarchical clustering on dataset was used on Pearson correlation of $\log 2(\mathrm{Hy} 3 / \mathrm{Hy} 5)$ intensities and all of the samples and miRNAs were clusterized using average linkage method. Principal Component Analysis (PCA) was also used to discriminate the different biological samples on the basis of the distances of a reduced set of new variables (Principal Components). Differentially expressed miRNAs between the two groups (MYC translocation-positive versus MYC translocation-negative) were identified with a two-tailed T-test with Welch approximation for different variance among groups and with different stringency criteria for false discovery rate (adjusted Bonferroni correction and no correction). Results of the test were filtered considering as differentially expressed only miRNAs with adjusted $p$-value less than 0,05 and fold change in absolute value greater than 1 [fold change = mean (group A) mean(group B)].

Quantitative Real-Time Polymerase Chain Reaction (RT-qPCR) Quantitative RT-PCR was performed to validate results of both miRNA and gene expression profiling, and to assess relative expression of $M Y C$ in ten $M Y C$ translocation 

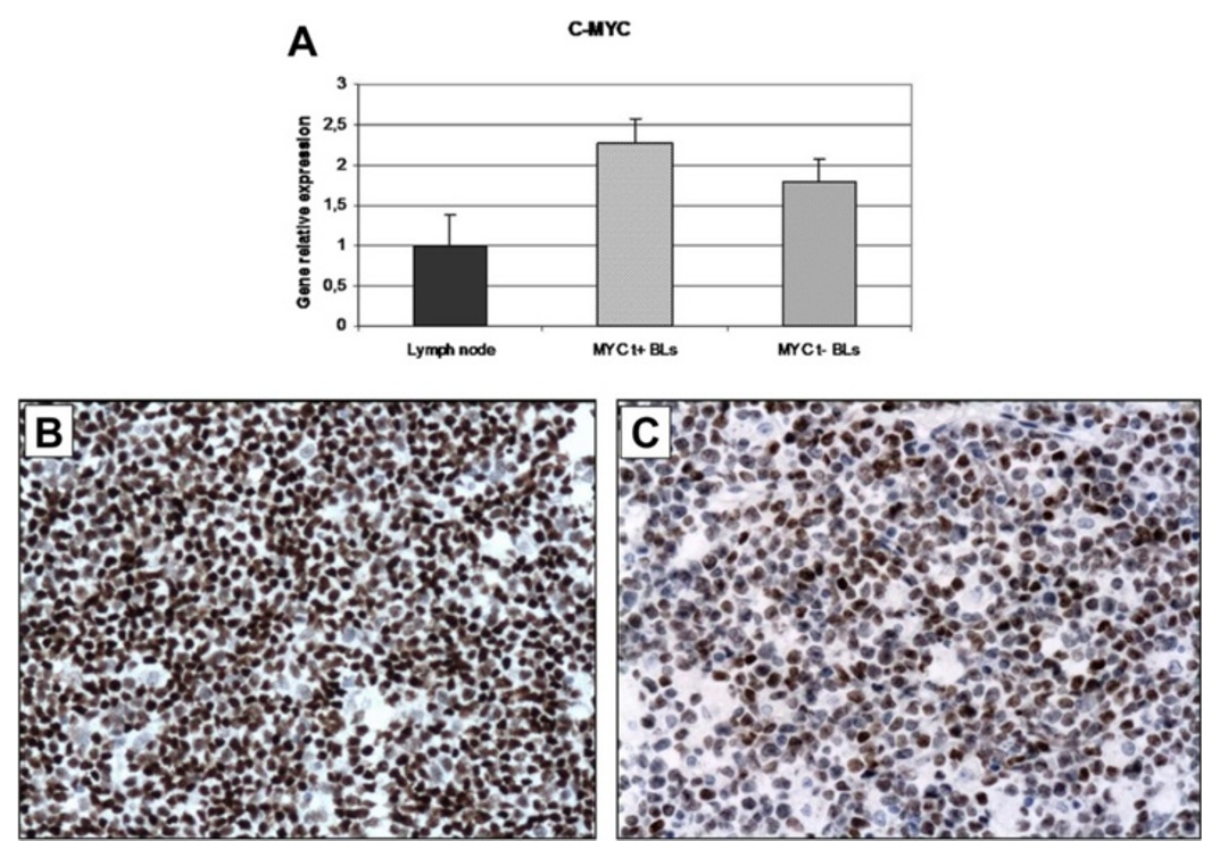

Fig. 1 MYC mRNA and protein expression in MYC translocation-positive and -negative BL cases. a Quantitative-RT-PCR. The expression of MYC was analysed at the mRNA level in cases either carrying or lacking the translocation. RT-qPCR results show the up-regulation of the gene also in the absence of MYC translocation; (b-c) Immunohistochemistry. In the exemplifying MYC translocation-positive case (b), a strong staining in about $95 \%$ of neoplastic cells is shown in contrast to the MYC translocation-negative one (c), in which the staining intensity was present in about $60 \%$ of cells. b-c: MYC stain. Original Magnification (O.M): 20x

positive and ten $M Y C$ translocation negative cases. For validation of differentially expressed miRNAs identified by profiling, RNA samples were reverse transcribed using the Universal cDNA synthesis kit (Exiqon, Copenhagen, Denmark), according to the manufacturer's instructions. RT-qPCR amplification was performed using microRNA LNA $^{\mathrm{Tm}}$ PCR primer sets (Exiqon, Copenhagen, Denmark) specific for hsa-miR-29a-b, hsa-miR-513a-5p, and hsamiR-628-3p, and using hsa-Let-7c as a reference gene. Validation of genes potentially targeted by the differentially expressed miRNAs (DNA (cytosine-5)-methyltransferase 1 (DNMT1), 3 alpha (DNMT3A), 3 beta (DNMT3B) was also carried out by RT-qPCR using FluoCycle SYBR green (Euroclone, Celbio, Italy) in $10 \mathrm{MYC}$-translocation positive and $10 M Y C$-translocation negative cases according to manufacturer's instructions. Non-neoplastic lymph nodes were meant as a negative control; HPRT was used as housekeeping gene. Primer sequences were designed using Primer-BLAST [32] and are reported in Table 1. Differences in gene expression were calculated using the $\Delta \Delta \mathrm{Ct}$ method [33].

\section{Immunohistochemistry}

Immunohistochemistry analysis for MYC (Abcam; dilution 1:200), DNMT1 (BD Biosciences: dilution 1:50), DNMT3A (Abcam; dilution 1:100), DNMT3B (Imgenex; dilution 1:200) and NMYC (ThermoScientific; dilution:1:100) was performed on Bond III automated immunostainer (Leica Microsystem, Bannockburn, IL, USA), with controls in parallel. No epitope retrieval was exploited. Ultravision Detection System using anti-Polyvalent HRP (LabVision, Fremont, CA, USA) and diaminobenzidine (DAB, Dako, Milan-Italy) as a chromogen was employed. The expression level of the proteins was evaluated in the ten $M Y C$ translocation-positive and ten $M Y C$ translocation-negative cases used for the RT-qPCR analysis, to validate results. Immunoreactivity was assessed by two investigators and cases with discrepancy were re-viewed to obtain a concordance ratio of more than $90 \%$. It is noteworthy that the definition of MYC positivity by immunohistochemistry is not universally standardized. However, the literature reports that having at least $40 \%$ of malignant lymphocytes with nuclear MYC expression is considered positive [34]; therefore we used this cut-off to discriminate positive and negative cases. For DNMT1 and DNMT3A, the cut-off level was based on modified Choi et al. system considering only the proportion of neoplastic cells showing a nuclear positivity [35]. The expression of DNMT1, DNMT3A and DNMT3B was considered absent/low if only $0-10 \%$ of tumor cells were stained; intermediate whether the positivity was present in $11-50 \%$ of neoplastic cells, and high when the immmunoreactive cells were $>50 \%$. For N-MYC, only nuclear staining was considered positive with no cut-off level. 


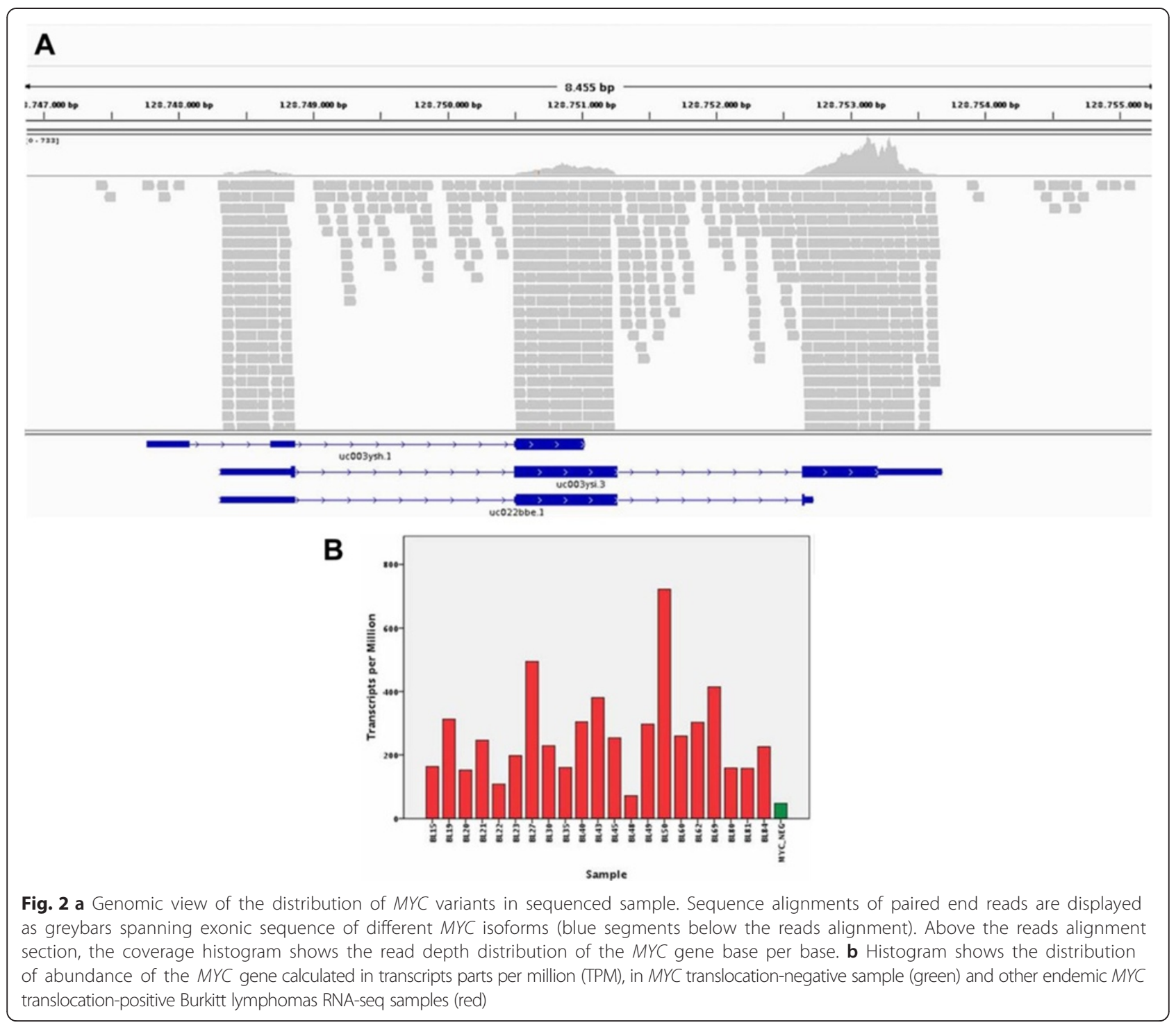

\section{Results}

MYC translocation-positive and MYC translocation-negative BL cases express MYC at both the mRNA and protein levels

We found that all of $M Y C$ translocation-positive cases expressed $M Y C$ at the mRNA and protein levels (Fig. 1a-c). By immunohistochemistry, a strong positivity was observed in about $95 \%$ of neoplastic cells. As far as $M Y C$ translocation-negative BLs is concerned, we observed that all the 10 samples expressed $M Y C$ mRNA at variable level (Fig. 1a). The same was true for MYC protein whose positivity was detectable in a percentage of neoplastic cells ranging from 50 to $80 \%$ (Fig. 1b-c). These findings confirmed that $M Y C$ translocation-negative cases used in this study, even lacking the typical $M Y C$ translocation, do express the MYC protein (Fig. 1c), suggesting the existence of alternative mechanisms regulating $M Y C$ expression.

\section{Next generation sequencing}

As we documented $M Y C$ expression in cases lacking the typical translocation, we sought to verify whether cryptic MYC abnormalities might have been missed by FISH analysis. To this aim, we studied by RNA-sequencing the only $M Y C$ translocation-negative $\mathrm{BL}$ case for which adequate material was available. Indeed, analysis of the MYC locus revealed a normal structure of $M Y C$ transcripts (Fig. 2 and Additional file 1: Table S1).

\section{MYC translocation-positive and MYC translocation-negative BL cases present with different microRNA expression patterns}

To ascertain whether there was a distinctive miRNA signature for $M Y C$ translocation-positive and negative BLs, we profiled ten $M Y C$ translocation-positive BLs and ten 


\section{A}

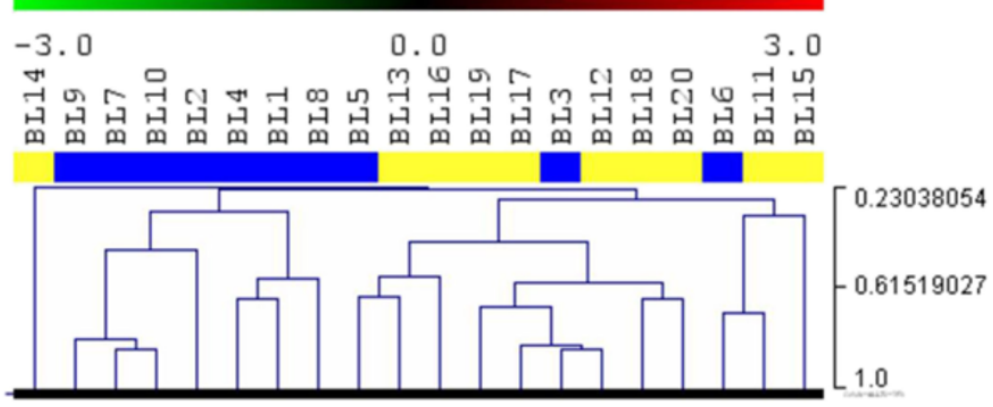

B

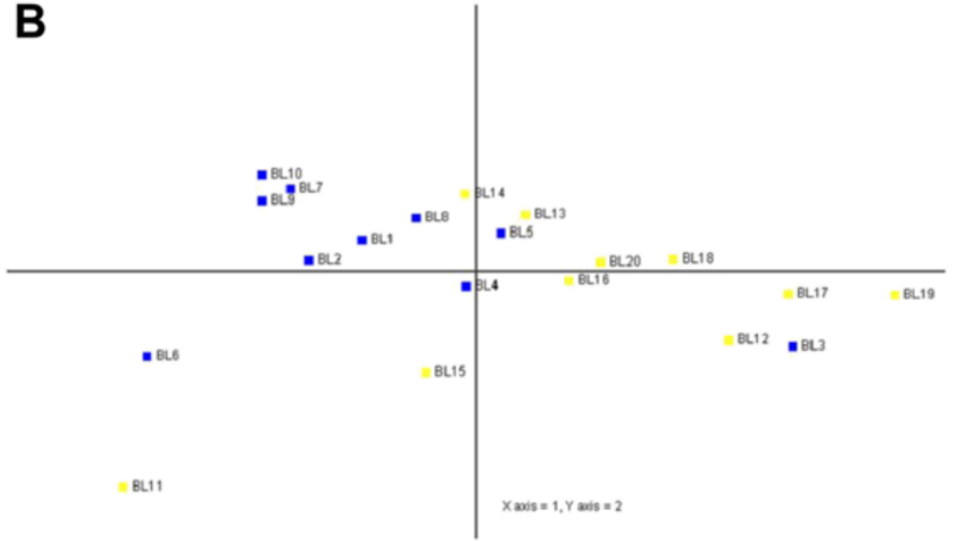

Fig. 3 Unsupervised analysis of Burkitt lymphomas. a The heat map diagram shows the result of the two-way unsupervised HC of miRNAs and samples based on the expression of 1,375 miRNAs. HC, roughly discriminated MYC translocation-negative (yellow) and MYC translocation-positive (blue) cases based on the miRNA expression pattern. In the matrix, each row represents a miRNA and each column represents a sample. The color scale illustrates the relative expression level of a miRNA across all samples: red represents an expression level above the mean and green represents expression lower than the mean. b PCA confirmed the distinction between MYC translocation-positive (blue) and MYC translocation-negative (yellow) samples

$M Y C$ translocation-negative BLs. Unsupervised hierarchical clustering $(\mathrm{HC})$ showed that MYC translocationpositive and -negative BLs could be roughly separated in two groups (Fisher exact test, $p=0.01$ ) (Fig. 3a). In addition, PCA confirmed the distinction between $M Y C$ translocation-positive and -negative samples (Fig. 3b). When a supervised approach was adopted, we identified 4 differentially expressed miRNAs out of 894 between $M Y C$ translocation-positive and -negative BLs, (T-test, $p$-values lower than 0.05 and fold change in absolute value greater than 1) (Fig. 4a-b and Table 2). Again, consistently with previous unsupervised analyses, the $\mathrm{HC}$ showed a clear distinction between $M Y C$ translocationpositive and -negative BLs (Fisher exact test, $p=0.001$ ).

By contrast, when we applied the previously described miRNA signature able to discriminate $\mathrm{BL}$ from diffuse large B-cell lymphomas (DLBCL) constituted by $30 \mathrm{miR}$ NAs containing $M Y C$-regulated and nuclear factor-kB pathways-associated miRNAs [36], we failed to discriminate $\mathrm{BL}$ cases according to the presence of $M Y C$ translocation, this ruling out bona fide the possible presence of DLBCLs morphologically mimicking classical BL in the present series (i.e. BL/DLBCL) [1]. Actually, hsamiR-29b that is up-regulated in DLBCL, is downregulated also in $\mathrm{BL}$ and mostly in $M Y C$ translocation negative cases.

Validation of the results was performed on all the dysregulated miRNAs so identified (hsa-miR-29a, hsa-miR29b, hsa-miR-513a-5p, and hsa-miR-628-3p). Quantification of these miRNAs was performed using RT-qPCR in all of the MYC translocation-positive and $10 M Y C$ translocation-negative cases. Collectively, fold changes of hsa-miR-29a, hsa-miR-29b, hsa-miR-513a-5p, and hsamiR-628-3p obtained by microarray results were confirmed by RT-qPCR (Fig. 4c). A significant downregulation of the miR-29 family members was observed in $M Y C$-translocation negative cases, whereas the remaining two miRNAs were hyper-expressed in the absence of translocation $(p<0.05)$.

\section{The microRNA pattern impacts on the gene expression} profiling (GEP) of BL cases

After identification of miRNAs discriminating $M Y C$ translocation-positive and $M Y C$ translocation-negative 


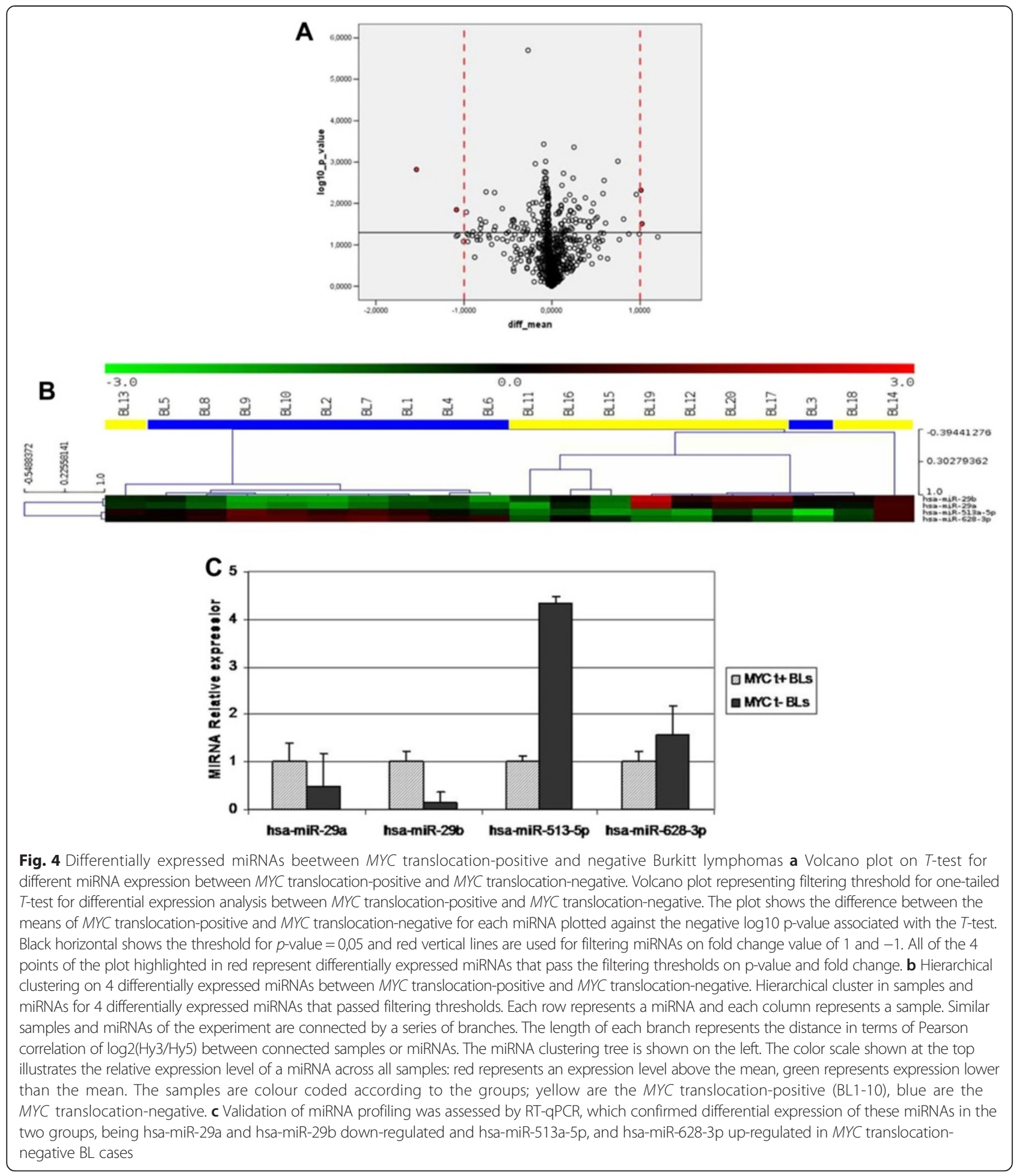

samples, we investigated whether they could affect the gene expression pattern of the tumors. 64 putative target genes of such miRNAs were identified by bioinformatics (Additional file 2: Table S2). Interestingly, the 64 predicted miRNA targets turned out to be significantly enriched in molecules involved in gene expression regulation, proliferation, and DNA modification (Additional file 3: Table S3) and included, among others $M Y C N$ and DNMT family members (1, $3 A$, and $3 B$ ), all known to be involved in malignant transformation.

Since a direct regulation of DNMT family members and MYCN by hsa-miR-29b has been previously demonstrated 
Table 2 miRNA profiling ( $p$-value and fold change)

\begin{tabular}{llll}
\hline TargetID & $p$ value & $\begin{array}{l}\text { Fold change } \\
\text { (Absolute value) }\end{array}$ & $\begin{array}{l}\text { Regulation in } \\
\text { MYC-neg }\end{array}$ \\
\hline hsa-miR-513a-5p & 0,031124841 & 1,02109958 & Down \\
hsa-miR-628-3p & 0,004815838 & 1,01011474 & Down \\
hsa-miR-29a & 0,0142882 & 1,086645638 & Up \\
hsa-miR-29b & 0,001516702 & 1,5403288 & Up \\
\hline
\end{tabular}

[36, 37], DNMT1, DNMT3A, DNMT3B and MYCN mRNA expression analysis was performed in a total of 10 $M Y C$ translocation-positive and $10 M Y C$ translocationnegative cases by RT-qPCR. Interestingly, increased expression of DNMT1, DNMT3 family members and $M Y C N$ was observed in $M Y C$ translocation-negative samples in comparison to the $M Y C$ translocation-positive cases and the control (Figs. 5a, 6a, 7a, 8a).

\section{DNMT1, DNMT3A, DNMT3B and NMYC protein expression in $B L$ tumour samples}

DNMTs and N-MYC protein expression was analyzed in $10 M Y C$ translocation-positive and $10 M Y C$ translocationnegative BL tumor samples by immunohistochemistry. In MYC translocation-positive BLs the positivity for DNMT1 was low/intermediate and ranged from $10 \%$ to $30 \%$ (Fig. 5b). In $M Y C$ translocation-negative cases, the expression of the protein was high; all the cases showed more than $70 \%$ positive cells (Fig. 5c). DNMT3A protein staining was high in both MYC translocation-positive and -negative BLs. However, only 3 out of 10 samples had a percentage of positive cells more than $40 \%$ (Fig. 6b) whereas all $M Y C$ translocation-negative BLs had more than $60 \%$ of neoplastic cells depicted by the antibody (Fig. 6c). In MYC translocation-positive BLs the positivity for DNMT3B was very low and ranged from $5 \%$ to $10 \%$ (Fig. 7b). In $M Y C$ translocation-negative cases, the expression of the protein was high; all the cases showed more than $70 \%$ positive cells (Fig. 7c). N-MYC protein expression was low in all the MYC translocation-positive BLs examined in which the staining was positive in about $5 \%$ of neoplastic cells (Fig. 8b). MYC-translocation negative samples demonstrated higher N-MYC positivity that was present in more than $90 \%$ of neoplastic cells (Fig. 8c).

\section{Discussion}

BL is an aggressive B-cell lymphoma with a characteristic clinical presentation, morphology and immunophenotype [1]. Over the past years, the typical translocation, involving the $M Y C$ oncogene and its variants, has been considered the molecular hallmark of this tumor. However, transcriptional and genomic profiling aimed to distinguish $\mathrm{BL}$ versus DLBCL revealed the existence of BLs without evident $M Y C$ translocation clustering with molecular BL. A recent paper reported that BLs lacking $M Y C$ translocation share a peculiar pattern of chromosome 11q aberration [38]. The significantly lower expression of $M Y C$ in such cases supported the view that $M Y C$ is not genomically activated, and the clinical, morphologic, and molecular characterizations of these cases suggest that they represent a distinct subset of $M Y C$-negative high-grade B-cell lymphomas with features resembling but not identical to BL. Yet, these findings do not explain the mechanisms through which some classic BL cases lack the typical genetic translocation involving $M Y C$ but do express $M Y C$ at the mRNA and the protein level [5, 6]. Dysregulation of $M Y C$ expression may be due to additional mechanisms, other than common genomic abnormalities, such as a miRNA imbalance $[39,40]$. So far, no data is available concerning the miRNA profile of MYC translocation-negative cases, besides the evidences previously reported by our group [5, 6]. In this study, we further explored the miRNA profile of BLs carrying or not the classical translocations involving the $M Y C$ gene.

Interestingly, when we compared the miRNA profiling of $M Y C$ translocation-positive versus MYC translocationnegative BL cases, we identified four miRNAs differentially expressed, of which hsa-miR-513a-5p and hsa-miR-628-3p were up-regulated and two miR-29 family members (hsamiR-29a and hsa-miR-29b) were down-regulated in $\mathrm{BL}$ cases lacking the $M Y C$ translocation.

Of note, microarray-based miRNA analysis turned out to be quite specific and robust in this study. In fact, all of the genes tested were successfully validated by RTqPCR.

Hsa-miR-628-3p and hsa-miR-513a-5p are less referred in the literature, whereas, more is known about the miR-29 family [41]. Interestingly, miR-29 family members have been related to malignant transformation, and it has been demonstrated that their down-regulation contributes to MYC-induced lymphomagenesis in vivo and in vitro models $[42,43]$. Thus, hsa-miR-29 family members down-regulation may represent an appealing possible mechanisms able to determine MYC up-regulation and sustain its expression at mRNA and protein level also in the absence of a translocation. Interestingly, a link between the miR-29 family by $M Y C$ has been recently reported [44], as repression of miR-29 by $M Y C$ through a corepressor complex with HDAC3 and EZH2 is observed in aggressive B-cell lymphomas [43]. This miRNA family may represent a novel target for tailored therapies as in vitro and mouse studies suggest increasing miR-29 expression by combined inhibition of HDAC3 and EZH2. Such an approach could help treat $M Y C$-overexpressing cancers [44]. In addition, it has been recently demonstrated that hsa-miR-29b directly binds to DNMT3A and $D N M T 3 B$, and regulates indirectly DNMT1 by targeting Sp1, a transactivator of the gene [36, 45]. In this scenario, over-expression of DNMT family members, due to hypo- 

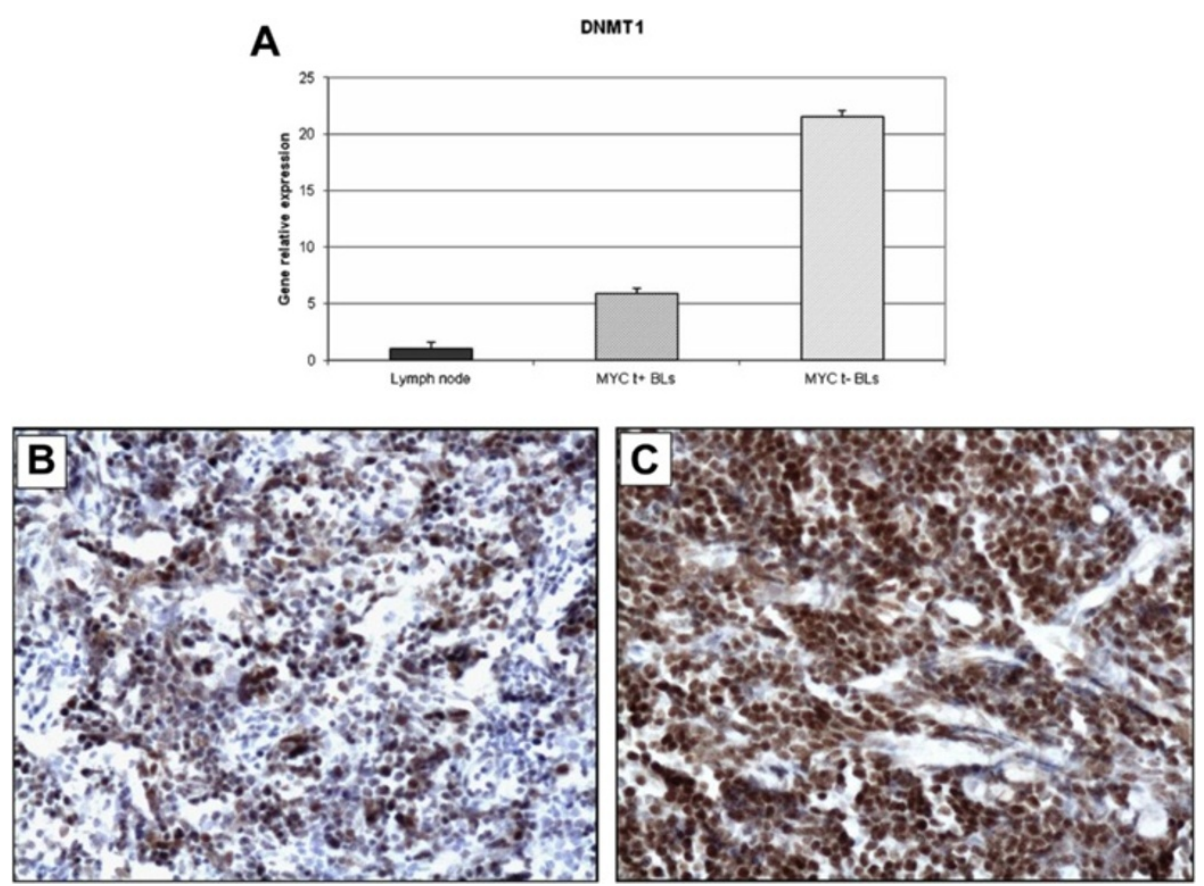

Fig. 5 RT-qPCR validation and immunohistochemical evaluation of DNMT1 in MYC translocation-positive and MYC translocation-negative BL primary tumors. a Quantitative-RT-PCR. The expression of DNMT1 was analysed at the mRNA level by RT-qPCR. The results show up-regulation of DNMT1 in cases lacking the translocation; (b-c) Immunohistochemistry. In the exemplifying MYC translocation-positive case (b), the staining is present in about $30 \%$ of neoplastic cells, in contrast to the MYC translocation-negative one (c), in which the positivity is depicted in about $80 \%$ of cells. b-c: DNMT1 stain. O.M: $20 \mathrm{x}$
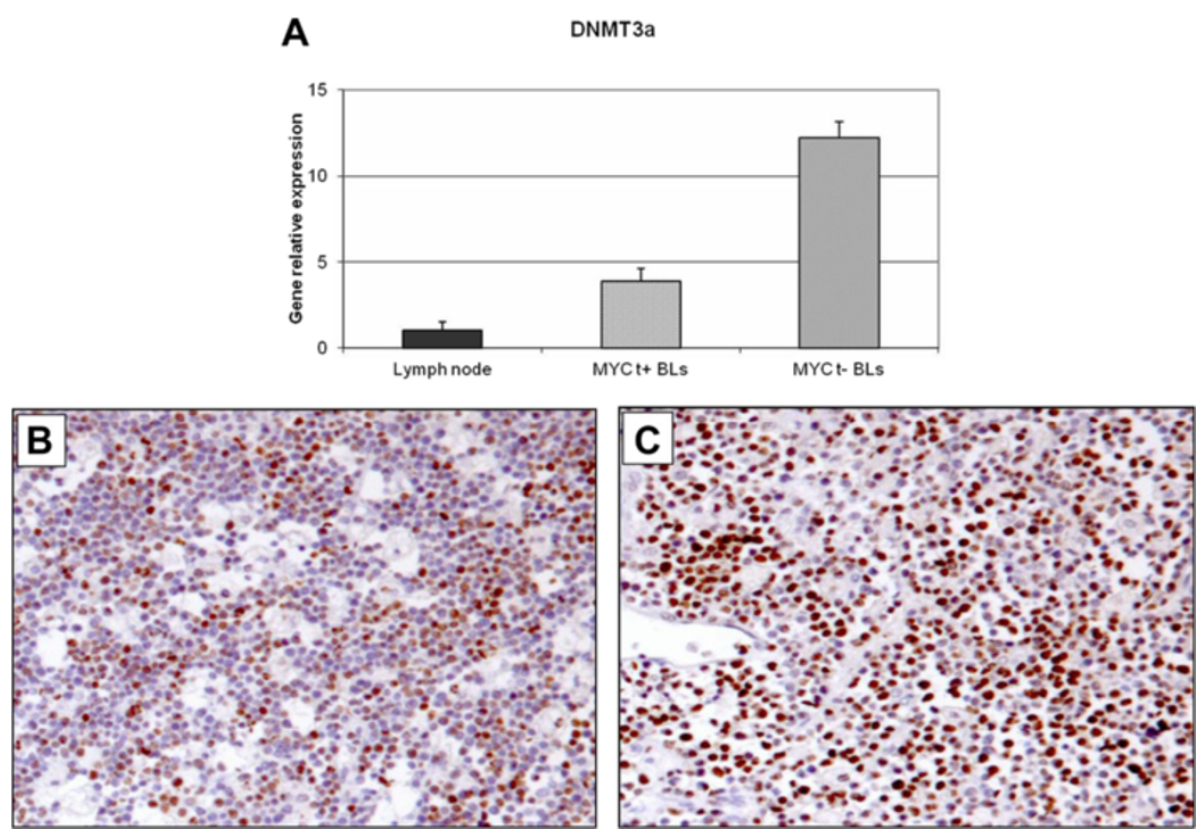

Fig. 6 RT-qPCR validation and immunohistochemical evaluation of DNMT3A in MYC translocation-positive and MYC translocation-negative BL primary tumors. a Quantitative-RT-PCR The expression of DNMT3A was analysed at the mRNA level by RT-qPCR. As for DNMT1, DNMT3A resulted up-regulated in cases lacking the translocation; (b-c) Immunohistochemistry. In the exemplifying MYC translocation-positive case (b), the staining is shown in $40 \%$ of neoplastic cells in contrast to the MYC translocation-negative one (c), in which about $60 \%$ of cells are positive. b-c: DNMT3A stain. O.M: 20x 

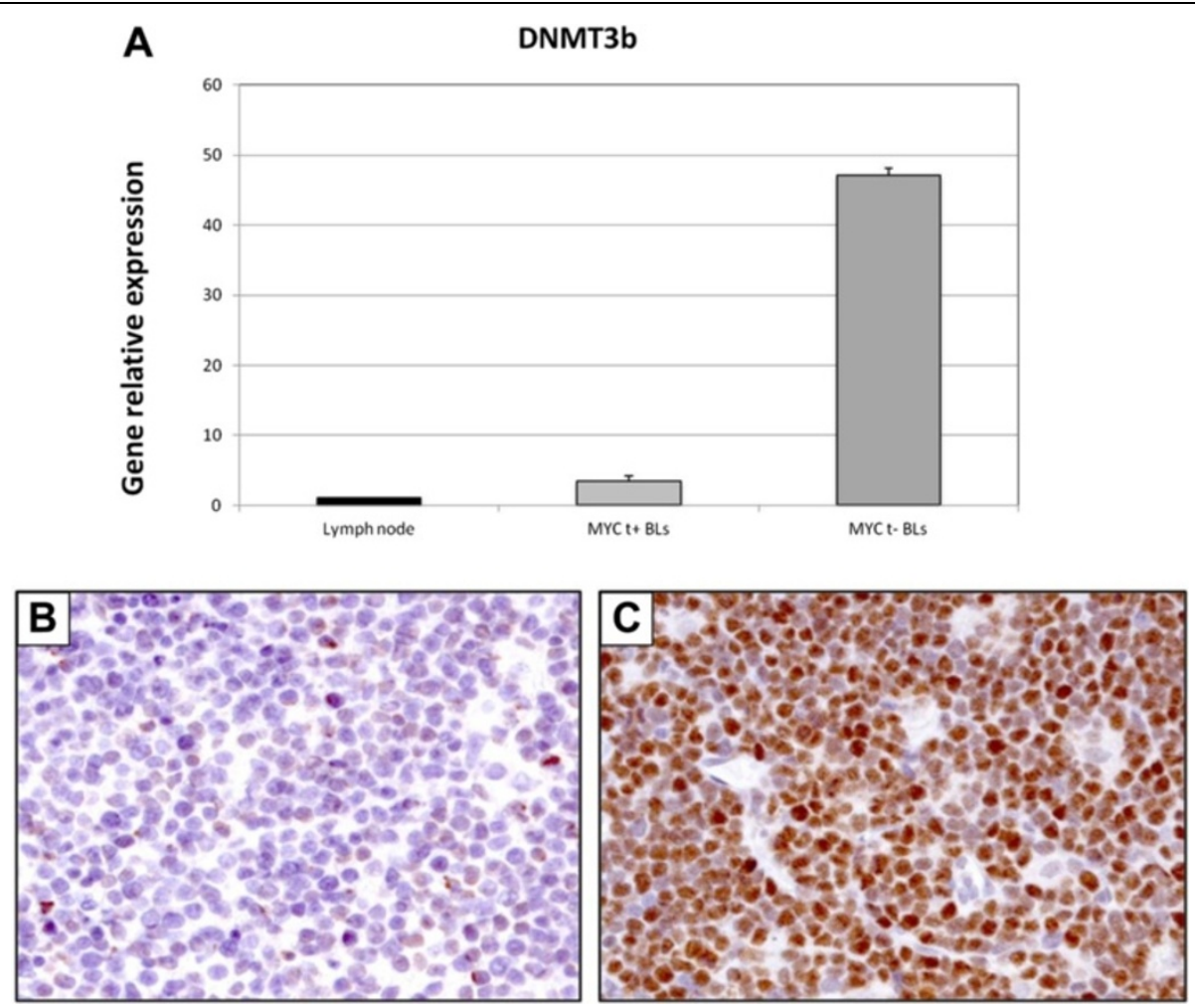

Fig. 7 RT-qPCR validation and immunohistochemical evaluation of DNMT3B in MYC translocation-positive and MYC translocation-negative BL primary tumors. a Quantitative-RT-PCR The expression of DNMT3B was analysed at the mRNA level by RT-qPCR. As for DNMT3A, DNMT3B resulted up-regulated in cases lacking the translocation; (b-c) Immunohistochemistry. In the exemplifying MYC translocation-positive case (b), the staining is shown in $5 \%$ of neoplastic cells in contrast to the MYC translocation-negative one (c), in which about $70 \%$ of cells are positive. b-c: DNMT3B stain. O.M: 20x

expression of hsa-miR-29 family members, may elicit a role in inducing carcinogenesis [46]. The finding that DNMTs were up-regulated in MYC translocation-negative BLs suggests an alternative way for the activation of lymphomagenesis in these cases, based on global changes in methylation landscape and loss of epigenetic control. Hsa-miR29a may favor this process by a synergistic hypermethylating effect [47]. In this regard, future studies exploring the global methylation patterns of BL with or without $M Y C$ translocation are definitely warranted.

We were also intrigued by the observation that another member of the $M Y C$ family, MYCN, was potentially dysregulated in BL cases lacking $M Y C$ translocation. Literature reports that MYC and N-MYC possess similar ability to induce cell proliferation and transformation although MYC may be more effective in some contexts. Over-expression of specific MYC family genes is frequently associated with particular types of human tumors [4]; $M Y C N$ deregulation is almost exclusively associated with solid tumors and only rarely observed in lymphomas. Nonetheless, both N-MYC and MYC are expressed in pro-B cells, and it has been demonstrated that N-MYC can support normal B-cell development in the absence of MYC [48-50]. Over-expression of either MYC or N-MYC under the control of the B cell-specific
$\mathrm{E} \mu$ enhancer results in development of pro-B cell lymphomas [51]. Finally, complex MYCN/IGH translocations frequently arise in mice deficient for p53, showing that, in this genetic background, the endogenous N-MYC can compete with MYC as a pro-B cell oncogenic translocation/amplification target [52]. Based on our findings (i.e. over-expression of N-MYC at the mRNA and protein levels in $M Y C$ translocation-negative cases) one should hypothesize that in $\mathrm{BL}$ cases lacking $M Y C$ translocation $\mathrm{N}-\mathrm{MYC}$ may represent an alternative cooperating mechanisms in contributing to malignant transformation. Interestingly, two of the differentially expressed miRNAs (miR513a-5p and miR-628-3p) have been recently reported dysregulated in human neuroblastomas, in which aberrant expression of $M Y C N$ is quite common [53, 54]. Of note, miR-628-3p expression seems even to correlate with tumors prognosis in such cases [55]. Altogether this observation suggests that $M Y C N$ aberrant expression itself may impact gene and microRNA expression pattern in BL cases lacking the typical $M Y C$ translocation. A large body of evidence has documented the existence of an active cross-talk between $M Y C$ itself and miRNAs machinery, suggesting the existence of a feedback loop between $M Y C$ and specific miRNAs [56]. This, in turn, might be the cause of a differential gene expression 

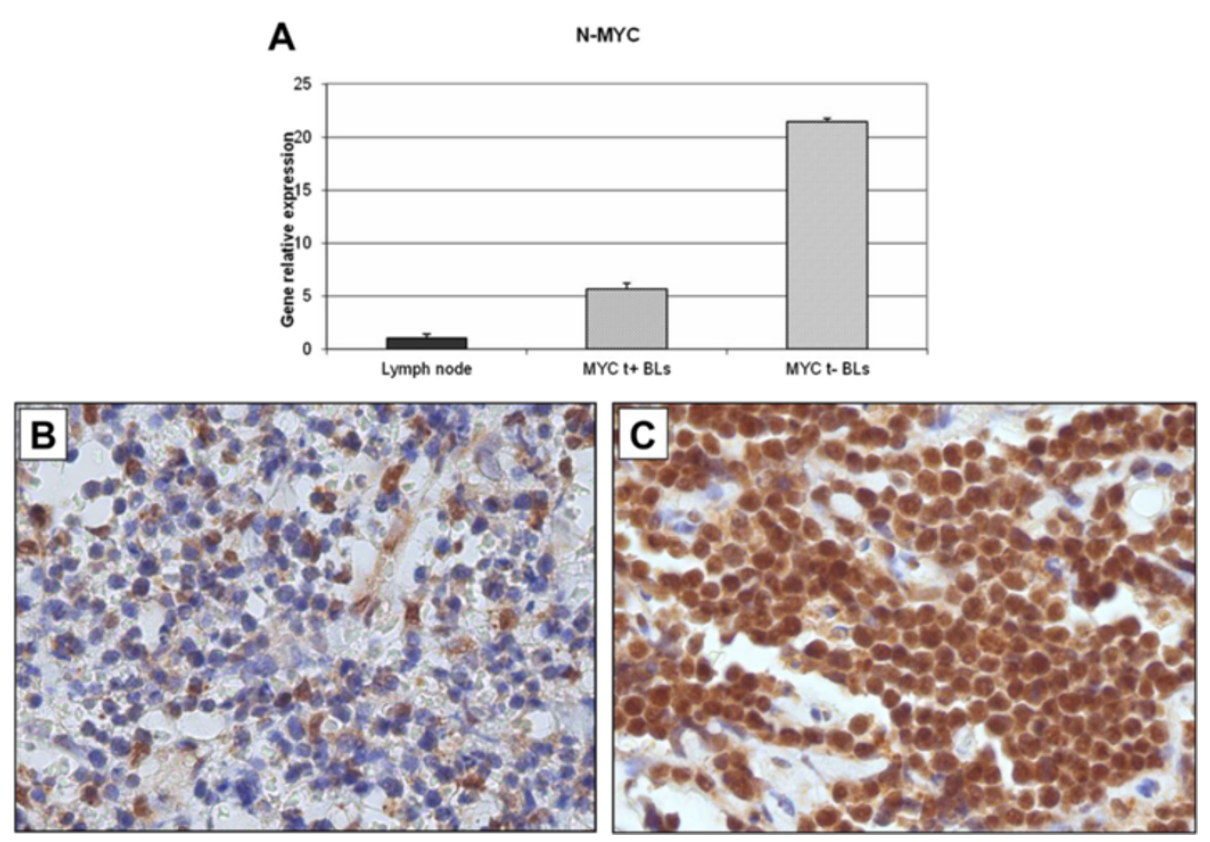

Fig. 8 RT-qPCR validation and immunohistochemical evaluation of N-MYC in MYC translocation-positive and MYC translocation-negative BL primary tumors. a Quantitative-RT-PCR The expression of NMYC was analysed RT-qPCR. MYC-translocation negative cases show a dramatic hyper-expression of the gene; altogether RT-qPCR results confirmed the bioinformatics predictions, which suggest a regulation of these by the miR29 family. Over-expression of the selected genes is in accordance with down-regulation of the miR-29 family observed in MYC-translocation negative cases; (b-c) Immunohistochemistry. In the exemplifying MYC translocation-positive case (b), the staining is present only in $5 \%$ of neoplastic cells in contrast to the MYC translocation-negative one (c), in which the positivity is detectable in about $90 \%$ of cells. b: H\&E, c: NMYC stain. b-c, O.M: 40x

and of functional alterations of neoplastic cells [40]. The difference in has-miR29 family members expression we detected between MYC translocation-positive and MYCtranslocation negative BL samples might be related to the lower MYC protein level among cases lacking the MYCtranslocation.

\section{Conclusions}

Our results extend the current knowledge on aggressive B-cell lymphomas presenting with MYC expression but lacking a conventional translocation. The evidences of $\mathrm{N}$ MYC and DNMT family member dysregulation point at a more complex scenario involving $M Y C$ and other players in BL tumorigenesis, and underline the role of a miRNAsMYC feedback loop. Therefore, MYC translocationnegative $\mathrm{BL}$ cases can represent a model to understand the intricate molecular pathways responsible for both $M Y C$ over-expression and its interaction with complex cellular processes.

\section{Availability of supporting data}

All the data used in this study have been deposited in the Gene Expression Omnibus (GEO) database. The accession number is GSE71471, and the link to freely access to all the information is http://www.ncbi.nlm.nih.gov/ geo/query/acc.cgi?acc=GSE71471.

\section{Additional files}

Additional file 1: Table S1. List of inter and intra chromosomal gene fusion detected by fusion-detection pipeline. (XLS $89 \mathrm{~kb}$ )

Additional file 2: Table S2. Predicted target genes of miRNAs differentially expressed in MYC translocation-positive and -negative BLs. (DOC $50 \mathrm{~kb}$ )

Additional file 3: Table S3. Gene set enrichment analysis for gene ontology categories of 64 genes predicted as targets of microRNAs differentially expressed in MYC translocation-positive and -negative BLs. (DOC $67 \mathrm{~kb}$ )

\section{Abbreviations}

BL: Burkitt lymphoma; DLBCL: Diffuse large B-cell lymphoma; DNMT: DNA methyltransferase; FFPE: Formalin fixed and paraffin embedded;

FISH: Fluorescence in situ hybridization; GATK: Genome Analysis Toolkit; GEP: Gene expression profiling; HC: Unsupervised hierarchical clustering; IGH: Immunoglobulin heavy chain gene; IGL: Immunoglobulin light chain gene; miRNAs: microRNAs; NGS: Next generation sequencing;

PCA: Principal component analysis; RT-qPCR: Quantitative Real-Time polymerase chain reaction; SNVs: Single Nucleotide Variants; WHO: World Health Organization.

\section{Competing interests}

The authors declare that they have no competing interests.

\section{Authors' contributions}

DFG, AMR, LL and PPP conceived and designed the experiments; OA, FF, ML, GS. performed the experiments; DFG, AMR, FF analyzed the data; BC, NM, EM, $\mathrm{RBJ}$, contributed reagents/materials/analysis tools; DFG, LL, AMR and PPP draft the paper, LL and SAP were responsible for funding. All authors read and approved the final manuscript. 


\section{Acknowledgements}

The Authors would like to thank the INCTR - Pathology Program and in particular Professor Martin Raphael and Kikkeri Naresh for their expert reviewing of the cases.

This work was supported by the Centro Interdipartimentale per la Ricerca sul Cancro "G. Prodi", Bologna AlL, AIRC 10007 5xMille - Prof. Pileri, AIRC IG 2013 N.14355 - Prof. Piccaluga, RFO (Prof. Pileri and Prof. Piccaluga), Progetto Strategico di Ateneo 2006 (Prof. Pileri and Prof. Piccaluga), and FIRB Futura 2011 RBFR12D1CB (Prof. Piccaluga). - Prof. Leoncini, Regional Health Research Program 2009. (Programma per la Ricerca Regionale in Materia di Salute- Direzione Generale del Diritto alla Salute e delle Politiche di Solidarietà) and PRIN 2010-2011.

\section{Author details}

'Department of Medical Biotechnologies, University of Siena, Italy - Via delle Scotte, 6 - 53100 Siena, Italy. ${ }^{2}$ School of Biological and Chemical Sciences, Queen Mary University of London, London, UK. ${ }^{3}$ Department of Experimental, Diagnostic, and Specialty Medicine, University of Bologna, Via Zamboni, 33, 40126 Bologna, Italy. ${ }^{4}$ Unit of Pathology, Brescia University, Piazza del Mercato, 15, Brescia, Italy.

\section{Received: 26 January 2015 Accepted: 28 September 2015} Published online: 09 October 2015

\section{References}

1. Swerdlow SH, Campo E, Harris NL, Jaffe E, Pileri S, Stein H. WHO classification of tumors of haematopoietic and lymphoid tissues. Lyon, France: IARC; 2008.

2. van Rijk A, Mason D, Jones M, Cabeçadas J, Crespo M, Cigudosa JC, et al. Translocation detection in lymphoma diagnosis by split-signal FISH: a standardised approach. J Hematop. 2008;1(2):119-26.

3. Evans PA, Pott C, Groenen PJ, Salles G, Davi F, Berger F, et al. Significantly improved PCR-based clonality testing in B-cell malignancies by use of multiple immunoglobulin gene targets. Report of the BIOMED-2 Concerted Action BHM4-CT98-3936. Leukemia. 2007;21(2):207-14.

4. Elaine S. Jaffe NLH, James W. Vardiman, Campo E. and Daniel A. Arber. Hematopathology. Edited by Elsevier. London, UK. 2011.

5. Leucci E, Cocco M, Onnis A, De Falco G, van Cleef P, Bellan C, et al. MYC translocation-negative classical Burkitt lymphoma cases: an alternative pathogenetic mechanism involving miRNA deregulation. J Pathol. 2008;216(4):440-50.

6. Onnis A, De Falco G, Antonicelli G, Onorati M, Bellan C, Sherman O, et al. Alteration of microRNAs regulated by c-Myc in Burkitt lymphoma. PLoS One. 2010;5(9):e12960.

7. Liao LM, Sun XY, Liu AW, Wu JB, Cheng XL, Lin JX, et al. Low expression of long noncoding XLOC_010588 indicates a poor prognosis and promotes proliferation through upregulation of c-Myc in cervical cancer. Gynecol Oncol. 2014;133(3):616-23.

8. Dews M, Tan GS, Hultine S, Raman P, Choi J, Duperret EK, et al. Masking epistasis between MYC and TGF- $\beta$ pathways in antiangiogenesis-mediated colon cancer suppression. J Natl Cancer Inst. 2014;106(4):dju043.

9. Terunuma A, Putluri N, Mishra P, Mathé EA, Dorsey TH, Yi M, et al. MYCdriven accumulation of 2-hydroxyglutarate is associated with breast cancer prognosis. J Clin Invest. 2014;124(1):398-412.

10. Wu DW, Hsu NY, Wang YC, Lee MC, Cheng YW, Chen CY, et al. c-Myc suppresses microRNA-29b to promote tumor aggressiveness and poor outcomes in non-small cell lung cancer by targeting FHIT. Oncogene. 2014. doi: 10.1038/onc.2014.152.

11. Zhang EB, Han L, Yin DD, Kong R, De W, Chen J. c-Myc-induced, long, noncoding $\mathrm{H} 19$ affects cell proliferation and predicts a poor prognosis in patients with gastric cancer. Med Oncol. 2014;31(5):914. doi:10.1007/s12032014-0914-7.

12. Schmitz R, Ceribelli M, Pittaluga S, Wright G, Staudt LM. Oncogenic mechanisms in Burkitt lymphoma. Cold Spring Harb Perspect Med. 2014;4(2):a014282. doi:10.1101/cshperspect.a014282.

13. Love C, Sun Z, Jima D, Li G, Zhang J, Miles R, et al. The genetic landscape of mutations in Burkitt lymphoma. Nat Genet. 2012;44:1321-5.

14. Richter J, Schlesner M, Hoffmann S, Kreuz M, Leich E, Burkhardt B, et al. Recurrent mutation of the ID3 gene in Burkitt lymphoma identified by integrated genome, exome and transcriptome sequencing. Nat Genet. 2012;44(12):1316-20.
15. Ott G, Rosenwald A, Campo E. Understanding MYC-driven aggressive B-cell lymphomas: pathogenesis and classification. Blood. 2013;122(24):3884-91.

16. Lee YS, Dutta A. MicroRNAs in cancer. Annu Rev of Pathol. 2009;4:199-227.

17. Fabbri M, Croce CM, Calin GA. MicroRNAs in the ontogeny of leukemias and lymphomas. Leuk Lymphoma. 2009;50(2):160-70.

18. Schuldiner O, Benvenisty N. A DNA microarray screen for genes involved in C-MYC and N-MYC oncogenesis in human tumors. Oncogene. 2001:20:4984-94.

19. Singh MD, Raj K, Sarkar S. Drosophila Myc, a novel modifier suppresses the poly $(\mathrm{Q})$ toxicity by modulating the level of CREB binding protein and histone acetylation. Neurobiol Dis. 2014;63:48-61. doi:10.1016/ j.nbd.2013.11.015. Epub 2013 Nov 27.

20. Naresh KN, Raphael M, Ayers L, Hurwitz N, Calbi V, Rogena E, et al. Lymphomas in sub-Saharan Africa-what can we learn and how can we help in improving diagnosis, managing patients and fostering translational research? $\mathrm{Br} J$ Haematol. 2011;154(6):696-703.

21. McPherson A, Hormozdiari F, Zayed A, Giuliany R, Ha G, Sun MG, et al. deFuse: an algorithm for gene fusion discovery in tumor RNA-Seq data. PLoS Computational Biology. 2011;7(5):e1001138.

22. Lyer MK, Chinnaiyan AM, Maher CA. ChimeraScan: a tool for identifying chimeric transcription in sequencing data. Bioinformatics. 2011;27(20). A.

23. Kim D, Salzberg SL. TopHat-Fusion: an algorithm for discovery of novel fusion transcripts. Genome Biol. 2011;12(8):R72.

24. Gupta R, Dewan I, Bharti R, Bhattacharya A. Differential expression analysis for RNA-Seq data. ISRN Bioinformatics. 2012;2012(817508):8.

25. McKenna A, Hanna M, Banks E, Sivachenko A, Cibulskis K, Kernytsky A. The Genome Analysis Toolkit: a MapReduce framework for analyzing next-generation DNA sequencing data. Genome Res. 2010;20:1297-303.

26. The 1000 Genomes Project Consortium. A map of human genome variation from population-scale sequencing. Nature. 2010;467:1061-73.

27. Wang K, Li M, Hakonarson H. ANNOVAR: Functional annotation of genetic variants from next-generation sequencing data. Nucleic Acids Res. 2010;38:e164.

28. Robinson JT, Thorvaldsdóttir H, Winckler W, Guttman M, Lander ES, Getz G, Mesirov JO. Integrative genomics viewer. Nat Biotechnol. 2011;29:24-6.

29. Quackenbush J. Microarray data normalization and transformation. Nat Genetics. 2002;32:496-501.

30. Cleveland WS. Robust locally weighted regression and smoothing scatterplots. J Amer Stat Ass. 1979;74:829-36.

31. Saeed Al, Sharov V, White J, Li J, Liang W, Bhagabati N, et al. TM4: a free, open-source system for microarray data management and analysis. Biotechniques. 2003;34(2):374-8.

32. Ye J, Coulouris G, Zaretskaya I, Cutcutache I, Rozen S, Madden T. Primer-BLAST: A tool to design target-specific primers for polymerase chain reaction. BMC Bioinformatics. 2012;13(1):134.

33. Livak KJ, Schmittgen TD. Analysis of relative gene expression data using real-time quantitative PCR and the 2(-Delta Delta C(T)) Method. Methods. 2001;25:402-8.

34. Mahmoud AZ, George TI, Czuchlewski DR, Zhang QY, Wilson CS, Sever CE, et al. Scoring of MYC protein expression in diffuse large B-cell lymphomas: concordance rate among hematopathologists. Mod Pathol. 2014. doi: 10.1038/modpathol.2014.140

35. Choi MS, Shim YH, Hwa JY, Lee SK, Ro JY, Kim JS, et al. Expression of DNA methyltransferases in multistep hepatocarcinogenesis. Hum Pathol. 2003;34(1):11-7.

36. Lenze D, Leoncini L, Hummel M, Volinia S, Liu CG, Amato T, et al. The different epidemiologic subtypes of Burkitt lymphoma share a homogeneous microRNA profile distinct from diffuse large B-cell lymphoma. Leukemia. 2011;25(12):1869-76.

37. Garzon R, Liu S, Fabbri M, Liu Z, Heaphy CE, Callegari E, et al. MicroRNA-29b induces global DNA hypomethylation and tumor suppressor gene reexpression in acute myeloid leukemia by targeting directly DNMT3A and 3B and indirectly DNMT1. Blood. 2009;113(25):6411-8.

38. Buechner J, Tømte $E_{1}$ Haug BH, Henriksen JR, Løkke C, Flægstad T, et al. Tumour-suppressor microRNAs let-7 and mir-101 target the protooncogene MYCN and inhibit cell proliferation in MYCN-amplified neuroblastoma. Br J Cancer. 2011;105:296-303.

39. Salaverria I, Martin-Guerrero I, Wagener R, Kreuz M, Kohler CW, Richter J, et al. A recurrent $11 \mathrm{q}$ aberration pattern characterizes a subset of MYCnegative high-grade B-cell lymphomas resembling Burkitt lymphoma. Blood. 2014;123(8):1187-98. 
40. Mott JL, Kurita S, Cazanave S, Bronk SF, Werneburg NW and FernandezZapico ME. Transcriptional suppression of miR29b-1/miR29a promoter by c-Myc, Hedgehog, and NF-kappaB. J Cell Biochem. 2010;110(5):1155-64.

41. Fabbri M, Garzon R, Cimmino A, Liu Z, Zanesi N, Callagari E, et al. MicroRNA29 family reverts aberrant methylation in lung cancer by targeting DNA methyltransferases 3A and 3B. Proc Natl Acad Sci U S A. 2007;104(40):15805-10.

42. Chang TC, Yu D, Lee YS, Wentzel EA, Arking DE, West KM, et al. Widespread microRNA repression by Myc contributes to tumorigenesis. Nat Genet. 2008;40(1):43-50.

43. Martinez I, Cazalla D, Almstead LL, Steitz JA, DiMaio D. miR-29 and miR-30 regulate B-Myb expression during cellular senescence. Proc Natl Acad Sci U S A. 2011:108(2):522-7.

44. Zhang X, Zhao X, Fiskus W, Lin J, Lwin T, Rao R, et al. Coordinated silencing of MYC-mediated miR-29 by HDAC3 and EZH2 as a therapeutic target of histone modification in aggressive B-Cell lymphomas. Cancer Cell. 2012;22(4):506-23.

45. Jiang $H$, Zhang $G$, Wu J, Jiang C. Diverse roles of miR-29 in cancer. Oncol Rep. 2014;31(4):1509-16.

46. Peters SL, Hlady RA, Opavska J, Klinkebiel D, Novakova S, Smith LM, et al. Essential role for Dnmt1 in the prevention and maintenance of MYC-induced T-cell lymphomas. Mol Cell Biol. 2013;33(21):4321-33.

47. Robaina MC, Mazzocoli L, Arruda VO, de Souza Reis FR, Apa GA, de Rezende LMM, et al. Deregulation of DNMT1, DNMT3B and miR-29 s in Burkitt lymphoma suggests novel contribution for disease pathogenesis. Exp Mol Pathol. 2015;98:200-7.

48. Strieder V, Lutz W. Regulation of N-myc expression in development and disease. Cancer Lett. 2002;180:107-19.

49. Malynn BA, de Alboran IM, O'Hagan RC, Bronson R, Davidson L, DePinho RA, et al. N-myc can functionally replace c-myc in murine development, cellular growth, and differentiation. Genes Dev. 2000;14:1390-9.

50. Rosenbaum H, Webb E, Adams JM, Cory S, Harris A. N-myc transgene promotes B lymphoid proliferation, elicits lymphomas and reveals crossregulation with c-myc. EMBO J. 1989;8:749-55.

51. Sheppard RD, Samant SA, Rosenberg M, Silver LM, Cole MD. Transgenic $\mathrm{N}$-myc mouse model for indolent B cell lymphoma: tumor characterization and analysis of genetic alterations in spontaneous and retrovirally accelerated tumors. Oncogene. 1998;17:2073-85.

52. Rooney S, Sekiguchi J, Whitlow S, Eckersdorff M, Manis JP, Lee C, et al. Artemis and p53 cooperate to suppress oncogenic N-myc amplification in progenitor B cells. Proc Natl Acad Sci U S A. 2004;101:2410-5.

53. Muthu M, Cheriyan VT, Munie S, Levi E, Frank J, Ashour AE, et al. Mechanisms of Neuroblastoma Cell Growth Inhibition by CARP-1 Functional Mimetics. PLoS One. 2014;9(7):e102567.

54. Schulte JH, Schowe B, Mestdagh P, Kaderali L, Kalaghatgi P, Schlierf S, et al. Accurate prediction of neuroblastoma outcome based on miRNA expression profiles. Int J Cancer. 2010;127(10):2374-85.

55. Schulte JH, Marschall T, Martin M, Rosenstiel P, Mestdagh P, Schlierf S, et al. Deep sequencing reveals differential expression of microRNAs in favorable versus unfavorable neuroblastoma. Nucleic Acids Res. 2010;38(17):5919-28.

56. Wu DW, Hsu NY, Wang YC, Lee MC, Cheng YW, Chen CY, et al. c-Myc suppresses microRNA-29b to promote tumor aggressiveness and poor outcomes in non-small cell lung cancer by targeting FHIT. Oncogene. 2015;34(16):2072-82

\section{Submit your next manuscript to BioMed Central and take full advantage of:}

- Convenient online submission

- Thorough peer review

- No space constraints or color figure charges

- Immediate publication on acceptance

- Inclusion in PubMed, CAS, Scopus and Google Scholar

- Research which is freely available for redistribution 